\title{
Quality of working life of academics and researchers in the UK: the roles of contract type, tenure and university ranking
}

Article

Accepted Version

Fontinha, R., Van Laar, D. and Easton, S. (2018) Quality of working life of academics and researchers in the UK: the roles of contract type, tenure and university ranking. Studies in Higher Education, 43 (4). pp. 786-806. ISSN 0307-5079 doi: https://doi.org/10.1080/03075079.2016.1203890 Available at https://centaur.reading.ac.uk/65856/

It is advisable to refer to the publisher's version if you intend to cite from the work. See Guidance on citing.

To link to this article DOI: http://dx.doi.org/10.1080/03075079.2016.1203890

Publisher: Taylor \& Francis

All outputs in CentAUR are protected by Intellectual Property Rights law, including copyright law. Copyright and IPR is retained by the creators or other copyright holders. Terms and conditions for use of this material are defined in the End User Agreement. 


\section{CentAUR}

Central Archive at the University of Reading

Reading's research outputs online 
Quality of Working Life of Academics and Researchers in the UK: The roles of contract type, tenure and university ranking

Rita Fontinha (corresponding author)

Henley Business School - University of Reading

Whiteknights, Reading, RG6 6UD

Tel: +44 (0) 1183785249

Email: r.fontinha@henley.ac.uk

Darren Van Laar

Department of Psychology - University of Portsmouth

St Andrew's Court, St Michael's Road,

Portsmouth PO1 2PR

Tel: +44 (0) 2392842980

Email: darren.van.laar@port.ac.uk

Simon Easton

Department of Psychology - University of Portsmouth

King Henry Building, King Henry 1st Street,

Portsmouth, PO1 2DY

Tel: +44 (0) 2392846304

Email: simon.easton@port.ac.uk 


\title{
Quality of Working Life of Academics and Researchers in the UK: The roles of Contract Type, Tenure and University Ranking
}

\begin{abstract}
Quality of Working Life has been defined as the part of overall quality of life that is influenced by work. We developed a mediation model where home-work interface, job and career satisfaction, control at work, and working conditions are considered to be positively related to employee commitment and to the absence of stress at work. These two variables were ultimately related to general well-being. We considered possible differences between workers with different contract types (permanent vs. temporary), as well as the roles of tenure and average position of the University in the UK rankings. Quantitative survey data from 510 academics and researchers working in 8 British Universities were analysed via a multi-group analysis with structural equation modelling (SEM). Our model presented a good fit, and a bootstrapping analysis confirmed the significance of indirect effects. Significant differences were found between permanent and temporary workers and striking results were found regarding tenure.
\end{abstract}

Keywords: British higher education; quality of working life; permanent vs temporary work; tenure; well-being 


\section{Introduction}

The Higher Education sector in the United Kingdom is strongly monitored, not only in terms of the quality of teaching provided, with the work of the Quality Assurance Agency for Higher Education (QAA), but also in terms of the quality of research, with national assessment systems such as the Research Excellence Framework (REF). This type of monitoring is of extreme importance as it contributes to the way higher education institutions are ranked, but it can also become a source of strain and decrease the quality of working life among those who work in higher education, specifically academics and researchers. In this study we focus on the factors that determine the overall quality of working life of academics and researchers in the UK. The three main aims of this study are: i) to theoretically develop and empirically test an established measure of quality of working life in higher education (Edwards et al., 2009); ii) to investigate the quality of working life of academics and researchers with different contract types, in particular permanent (i.e., open-ended contracts) vs. temporary (fixed-term contracts); iii) to explore the impact of tenure (i.e. number of years/months worked) and of the average positioning of an individual's University in the UK rankings, on the different dimensions that compose quality of working life.

Firstly, we draw on the conservation of resources (COR) theory (Hobfoll 1989) and on the social exchange theory (Blau 1964) in order to develop a mediation model explaining the relationships between the different factors within quality of working life (QoWL). In particular, we focus on six dimensions identified in previous research (Easton and Van Laar 2012; Easton and Van Laar 2013; Edwards et al. 2009): Home-Work Interface (HWI), Working Conditions (WCS), Job and Career Satisfaction (JCS), Control at Work (CAW), Stress at Work (SAW), and General Well-Being (GWB), and consider an additional proposed factor - Employee Commitment to the Organisation (ECO). We develop a mediation model where employees' perceptions of a specific set of work characteristics (HWI, WCS, JCS and 
CAW) relate, not only to occupational health, assessed via the perceived absence of SAW, but also to employees' attitudes towards their University, assessed via the levels of ECO. It is posited that the perceived absence of stress at work and high commitment to the University ultimately be positively related to employees' general well-being. The development of this mediation model contributes to existing research on quality of working life as it explores the processes through which different work and organisation-related dimensions might ultimately influence general well-being.

The second aim of this study relates to the role of contract type on the different dimensions within quality of working life. It is anticipated that temporary contracts (vs. permanent contracts) are more likely to be associated with more job insecurity. However, recent research on temporary work consistently demonstrates that the negative impacts of job insecurity on well-being tend to be significant for permanent workers, but not for temporary workers (e.g., Bernhard-Oettel, Sverke \& De Witte 2005; De Cuyper and De Witte 2006, 2007; De Cuyper, Notelaers and De Witte 2009; De Cuyper et al. 2010; Kirves et al. 2011). This can be seen as being associated with the content of their psychological contracts, meaning that temporary workers may tend to be more likely to expect job insecurity a priori. In this study, we aim to extend this body of research and evaluate the differences between permanent and temporary academics and researchers, not only in terms of their average scores in all different components of quality of working life, but also in terms of the paths that explain the links between these different components, resulting in general well-being (via a multi group structural equation modelling analysis).

The third aim of this study is to investigate the effect of objective variables such as tenure and average positioning of one's University in the UK rankings, on the different dimensions that constitute quality of working life. We anticipate that the longer temporary workers keep their temporary status (Galais and Moser 2009), the more negative 
consequences it will have for their quality of working life, when compared with permanent workers. Furthermore, we hypothesise that the average positioning of an individual's University in the rankings is likely to be perceived as a factor of esteem, and so may be related to higher scores in the different factors within quality of working life for both permanent and temporary workers. The assessment of these additional variables is another innovative feature of this study, and it is of relevance as the length of work and the reputation of the organisation/University are likely to be particularly important for workers in higher education.

The following sections of the paper will present the theoretical rationale behind our hypotheses. Thereafter, we will describe the methods used to collect and analyse data. We will finally describe the results and discuss them, considering implications for theory and practice.

\section{A mediation model for Quality of Working Life}

Work-related stress has been reported to be widespread in higher education in the UK (e.g., Tytherleigh et al. 2005) and in many other countries (e.g., Gillespie et al. 2001; Zhang 2007). The main aspects associated with stress include job insecurity, poor work relationships, lack of job control, inadequate resources, poor communication (Tytherleigh et al. 2005), lack of support and poor work-life balance (Kinman et al. 2006). These findings suggest that the absence of work-related stress is perhaps associated with a set of resources that may or may not be available to the individual. The COR model (Hobfoll 1989) postulates that individuals seek to acquire and maintain resources, including objects, personal characteristics, conditions, and energies, and that stress occurs when there is a loss (or threat of loss) of these resources. In this particular study we focused on conditions related to perceived work characteristics. Firstly, a balanced work-family interface, also addressed in 
previous literature as work-life balance, is here expected to be considered a positive resource for individuals and positively related to the absence of stress, as demonstrated in previous empirical studies (e.g. Chiang, Birtch and Kwan 2010). Second, the existence of adequate working conditions, specifically concerned with physical resources necessary to perform one's job are also here expected to be relevant predictors of the absence of stress at work (e.g., Evans and Johnson 2000). Third, an individual's satisfaction with his or her current position and career path can be seen as an important work-related resource which is likely to be associated with the absence of stress at work (Borg, Riding and Falzon 1991). Finally, the existence of control over decision making at work has been widely studied with Karasek's (1979) demands-control model, which suggests that control (whether actual or perceived) is an important resource to deal with the actual or perceived demands of a job and thus will be positively associated with the absence of stress. Based on this rationale, we hypothesise:

H1a) Work characteristics such as a balanced home-work interface, good physical working conditions, job and career satisfaction, and control at work are positively related to the absence of work-related stress.

Organisational commitment has been a widely researched construct and Meyer and Allen's (1997) three-component model of commitment is one of the most frequently used frameworks. In this model, affective commitment is defined as an emotional attachment to, identification with, and involvement in the organisation; continuance commitment denotes the perceived costs associated with leaving the organisation; and normative commitment reflects a perceived obligation to remain in the organisation (Meyer and Allen 1997). For this assessment of quality of working life we focus on the affective dimension of commitment, which is one of the most relevant forms of commitment as empirical research has consistently demonstrated that it is related to outcomes such as reduced turnover and turnover intentions, 
low absenteeism, more organisational citizenship behaviours, improved performance and improved well-being (Meyer et al 2002). We will focus on the antecedents of this form of commitment, by considering the importance of social exchange (Blau 1964) and the norm of reciprocity (Gouldner 1960). According to this theory and its inherent norm, employees will tend to feel the need to reciprocate when they perceive that they are receiving favourable inducements by their employers. The model suggests that they will tend to reciprocate by developing favourable attitudes (such as organisational commitment) and by demonstrating favourable behaviours in the organisation. For this reason, considering the overall model of quality of working life, we anticipate that employees who perceive work-related characteristics (home-work interface, working conditions, job and career satisfaction, and control over decision making) as favourable to them, are likely to reciprocate with high levels of commitment to the organisation. In particular, we anticipate that a balanced home-work interface will be perceived as an inducement and employees will be more committed to their organisation, as suggested by previous evidence in different settings (e.g. Huang, Lawler and Lei 2007). Due to the same exchange mechanisms, good working conditions would also be expected to be significantly and positively related to commitment to the organisation (McGuire and McLaren 2009). Furthermore, job and career satisfaction would also be seen as a work-related characteristic which is likely to be positively related to organisational commitment (e.g. Andolsek and Stebe 2004). Additionally, control over decision making at work should also be positively related to employee commitment to the organisation (Zaffane 1994). Accordingly, we hypothesise:

H1b) Work characteristics such as a balanced home-work interface, good physical working conditions, job and career satisfaction and control at work are positively related to employee commitment to the organisation. 
We additionally anticipate that a favourable perception of the above mentioned work characteristics (HWI, WCS, JCS and CAW) is associated with higher levels of general wellbeing. However, we believe that this relationship is not direct. For the above mentioned reasons, we believe that employees' perceptions about their working conditions will first be related to stress at work and to the commitment to their organisation (in this case their current University), and these variables will ultimately be positively associated with general wellbeing. The core reasoning behind this mediation structure relates to the fact that one's perception about specific work characteristics is likely to first shape one's attitudes toward the organisation (organisational commitment) and the perceived occupational health (absence of stress at work), and these work-focused attitudes would only then influence a more general perception of well-being. The absence of stress at work is likely to be positively related to general well-being, as suggested in previous research (Daniels and Guppy 1994) and, previous studies have consistently found a significant positive relationship between organisational commitment (specifically affective commitment) and employee well-being (see Meyer and Maltin 2010, for a review). For these reasons we developed the three following hypotheses:

H1c) The absence of stress at work and employee commitment to the organisation are positively related to general well-being.

H1d) The absence of stress at work mediates the positive relationships between work characteristics such as a balanced home-work interface, good physical working conditions, job and career satisfaction and control at work, and general well-being.

H1e) Employee commitment to the organisation mediates the positive relationships between work characteristics such as a balanced home-work interface, good physical working conditions, job and career satisfaction and control at work, and general well-being. 


\section{The Quality of Working Life of Permanent vs. Temporary Academics and Researchers}

The higher education sector is characterised by the existence of numerous fixed-term contracts, both for teaching and for research purposes. Permanent (open-ended) contracts and temporary (fixed-term) contracts can have very different implications for their employees, and this is particularly related to the fact that the second group can experience more job insecurity. Previous research demonstrated that perceived job insecurity can be associated with reduced levels of actual or perceived well-being (for meta-analyses, see Cheng and Chan 2008; Sverke, Hellgren and Näswall 2002). In the particular context of academia, job insecurity has been considered a key potential source of stress or distress (Gillespie et al. 2001; Tytherleigh et al. 2005). However, more recent research across different sectors, including higher education (e.g. Kirves et al. 2011), has consistently found that the negative impacts of job insecurity on well-being are significant for permanent workers, but not for temporary workers (e.g., Bernhard-Oettel, Sverke and De Witte 2005; De Cuyper and De Witte 2006, 2007; De Cuyper, Notelaers and De Witte 2009; De Cuyper et al. 2010; Kirves et al. 2011). A proposed explanation for this draws upon one of the constructs stemming from the social exchange theory (Blau 1964) and its inherent norm of reciprocity (Gouldner 1960): the psychological contract. The psychological contract refers to employees' perceptions of reciprocal expectations and obligations implied in the employment relationship (Guest 2004; Rousseau 1995).

While permanent workers might be more likely to expect their employer to provide them with job security, temporary workers may be more likely to expect job insecurity as something inherent to their psychological contracts (De Cuyper and De Witte 2006, 2007). For this reason, the perception of job insecurity can be conceptualised as more likely to be negatively related to the well-being of permanent workers, but is impact on temporary workers' well-being might be milder. Due to their reduced expectations, temporary workers 
are here predicted to perceive work characteristics (HWI, WCS, JCS and CAW) in a more favourable manner than permanent workers:

H2a) Academics and researchers with temporary (fixed-term) contracts are likely to have higher ratings in terms of work characteristics (HWI, WCS, JCS and CAW), when compared to academics and researchers with permanent (open-ended) contracts.

While the previous hypothesis focuses on mean differences between permanent and temporary academics and researchers regarding work characteristics, we also aim to further investigate how the paths between these variables and the remaining variables in our hypothesised mediation model will operate for the two groups of workers. Considering the temporary nature of their contracts, temporary workers might be expected to be most likely to differ from permanent workers in what concerns organisational commitment. It is generally assumed that short contract duration is negatively related to organisational commitment (see De Cuyper et al. 2008, for a review). For this reason, it is likely that no matter how good are temporary workers' perceptions about work characteristics (HWI, WCS, JCS and CAW), the knowledge that work will be transitory will make it less likely that they will develop a strong committed to the organisation, when compared to permanent workers. This means that the paths from HWI, WCS, JCS and CAW to ECO will be weaker for temporary workers, when compared to permanent workers. Our hypothesis reads as follows:

$\mathrm{H} 2 \mathrm{~b}$ ) Work characteristics such as a balanced home-work interface, good physical working conditions, job and career satisfaction and control at work have a weaker impact on employee commitment to the organisation for temporary workers, when compared to permanent workers. 


\section{The roles of Tenure and University Rank}

Temporary work is often assumed to have a stepping-stone function, i.e. individuals often take on temporary jobs considering that there might be a possibility of moving to a permanent contract at a later stage (De Cuyper, De Witte and Van Emmerick 2011). The longer a temporary worker stays in a temporary contract (or in a series of temporary contracts), the less likely it may be that they will perceive their status as a stepping stone rather than a dead end, which might have negative implications for their quality of working life. It can be suggested that this would be particularly true in academia, where competition for permanent positions is often intense. For this reason, we anticipate that the longer temporary workers keep their temporary status (Galais and Moser 2009), the more negative consequences it will have for their quality of working life, when compared to permanent workers. Our hypothesis reads as follows:

H3) A longer tenure in the organisation is negatively related to higher scores in the different factors within quality of working life for temporary workers, but not for permanent workers.

We anticipate that the quality of working life of academics and researchers in the UK is also likely to be influenced by the status of the University that they work for. In the UK, University rankings are a debatable topic. However, they are of great importance as they can affect the University's perceived reputation among applicants (not only national, but also international). Previous research indicates that organisational attractiveness is related to more willingness to work for that employer (Turban and Greening 1997). The average positioning of one's University in the rankings is likely to be perceived, not only as a source of better working conditions (resources), but also as a factor of esteem and reputation, which suggests 
that it may be related to higher scores in the different factors within quality of working life for both permanent and temporary workers. We hypothesise:

H4) Working for an organisation with a higher average position in the UK University rankings is positively related to higher scores in the different factors within quality of working life for both permanent and temporary workers.

\section{Method}

\section{Data collection}

Data were collected in eight British Universities. The eight universities that participated in the study were from a wide range of positions in the university rankings (The Complete University Guide, University League Tables by The Guardian and Times Higher Education). Since positions in the rankings change every year, we considered a weighted average of the Universities' positions in 2011, 2012 and 2013. Our overall aim was to identify and recruit Universities that would be heterogeneously distributed across the ranking, in order to make our conclusions regarding the quality of working life of academics and researchers in the UK more generalizable. We contacted several Universities in the UK asking them to participate in our study. We were aware that several Universities would possibly decline our research request, but we wanted to make sure that we would have a sample that would be representative of the different positions in the UK rankings. We calculated the sample size needed for each quarter of the rank considering a Z-score of 1.96, a standard deviation of .5 and a margin of error of $+/-5 \%$, which resulted in 385 respondents needed. In order to achieve the desired sample size, we decided to have at least two Universities from each quarter in the rankings. In particular, two Universities were from the upper quarter of the rankings, two from the second quarter, two from the third quarter, and two from the bottom quarter $(61.5 \%, 19.2 \%, 4.7 \%$ and $14.6 \%$ of respondents, respectively). 
Although employees from top ranked Universities are over represented, the response rates based on the total number of employees are larger for lower ranked Universities (response rates for all University categories: upper quarter $21.75 \%$; second quarter $24.87 \%$; third quarter $10.23 \%$; bottom quarter 52.25\%). The unbalanced distribution per rank does not affect our results as we test ranking position as a predictor of the different factors within quality of working life in our model.

All employees of these Universities were invited via an email sent by the Human Resources department to fill out online confidential questionnaires, which resulted in a total of 3771 responses. For the purpose of this study, we deleted all responses belonging to employees who were not academics nor researchers. We also deleted all responses of academics and researchers who worked part-time for the University, and decided to compare only academics and researchers who worked full-time (i.e., for whom this was their main job). This resulted in a total of 1095 employees. The academics and researchers held two different contract types: permanent $(n=840)$ and temporary $(n=255)$.

\section{Participants}

Unbalanced samples may influence the results of multiple group analyses (Brown 2006). For this reason, we randomly eliminated 585 permanent employees from the sample. This process allowed us to keep balanced sample sizes between the permanent and temporary subsamples. We have then performed tests for equality of variances in order to compare the sample of permanent workers removed $(n=585)$ with the sample of permanent workers that remained in the final dataset $(n=255)$. We found no significant differences between the two groups concerning gender distribution $(F=.76 ; p=.38)$, age $(F=1.60 ; \mathrm{p}=.21)$, tenure in the university $(F=2.65 ; p=.10)$ and university ranking $(F=1.29 ; p=.26)$. At a later stage, we have also inspected possible differences between the groups of permanent workers 
maintained or removed from the study by focusing on the factors within quality of working life - no significant differences were detected (HWI: $F=.02 ; p=.90 /$ WCS: $F=1.57 ; p=$ $.21 / \mathrm{JCS}: F=.11 ; p=.74 / \mathrm{CAW}: F=.00 ; p=.98 / \mathrm{OCM}: F=.09 ; p=.77 / \mathrm{SAW}: F=.02$ $p=.89 /$ GWB: $F=.15 ; p=.70)$.

The final sample of this study included a total of 510 academics and researchers, 255 with permanent contracts and 255 with temporary contracts. There were differences between temporary and permanent workers on most background characteristics. First, there was a higher percentage of females in the temporary $(n=155,60.8 \%)$ compared with the permanent $(\mathrm{n}=100,39.2 \%)$ sample, $\chi^{2}(1)=18.08, \mathrm{p}<.001$. Second, the temporary sample was on average younger $(2.11$ in the age categorical variable, where $1=$ under 25 years; $2=$ 25 to 44 years; $3=45$ to 59 years; $4=60$ years or over $)$ than the permanent sample $(2.70 ; \mathrm{F}=$ $66.55, \mathrm{p}<.001)$, and organisational tenure was lower for temporary workers $(2.10$ in the 'years worked' categorical variable where $1=$ less than one year; $2=1$ to 2 years; $3=3$ to 5 years; $4=6$ to 10 years; $5=11$ to 20 years; $6=$ more than 20 years) than for permanent workers $(3.23 ; \mathrm{F}=59.48, \mathrm{p}<.001)$. Third, temporary workers were more predominantly employed by higher ranked universities (47.21 - a lower value represents a higher rank), compared to permanent workers $(69.15 ; \mathrm{F}=137.49, \mathrm{p}<.001)$.

\section{Measures}

Quality of working life. Quality of working life was measured with Easton and Van Laar's (2012) WRQoL (Work-Related Quality of Life) 23-item scale. The original WRQoL 23-item scale includes six factors reflecting different elements that characterise one's quality of working life: Home-Work Interface (HWI), Working Conditions (WCS), Job and Career Satisfaction (JCS), Control at Work (CAW), Stress at Work (SAW), and General Well-Being (GWB). The WRQoL scale has been used in a wide range of settings and organisations 
across the world and has been translated into various languages (e.g., Blanch et al. 2010; Dehghan, Tahmineh and Asadi 2011; Easton and Van Laar 2013; Vagharseyyedin et al. 2011). In order to increase the comprehensiveness of the scale, we included three additional items generated from the literature in order to capture employees' commitment to the organisation (ECO) (Meyer and Maltin, 2010). All items are scored on a five-point Likert scale from 1 = "Strongly disagree" to 5 = "Strongly agree". A detailed description of each factor is presented below. Items within each factor, and their respective factor loading, are presented on Appendix 1.

Home-Work Interface (HWI). This factor is based on three items associated with accommodation of family and work commitments. The HWI factor has a sub-scale reliability of $\alpha=.85$ within the WRQoL scale, and addresses work-life balance (e.g., Lewis, Gambles and Rapoport 2007).

Working Conditions (WCS). The WCS factor is based on three questions related to the physical working environment, which is a key element related to occupational health, in particular exhaustion (Demerouti et al. 2001). Reliability for this sub-scale was $\alpha=.77$.

Job and Career Satisfaction (JCS). The JCS factor was measured with five items assessing the degree to which the workplace provides a person with the things that make them feel good, such as sense of achievement, high self-esteem, and fulfilment of potential. This factor is highly correlated with other measures of job satisfaction (Easton \& Van Laar 2012) and presents a sub-scale reliability of $\alpha=.83$.

Control at Work $(C A W)$. The three items on the CAW factor are associated with sense of control over decisions at work, which has implications for health and well-being (Spector, 2002). The reliability was of $\alpha=.85$.

Stress at Work (SAW). Four items were used to measure the extent to which an individual perceives they are subject to excessive pressure or experience of stress at work. 
The SAW factor has a sub-scale reliability of $\alpha=.83$. The items were reversed, thus for data analyses we present the SAW factor meaning Absence of Stress at Work.

Employee Commitment (ECO). In addition to the original six WRQoL factors, three items were included in order to further develop the scale, in particular to provide an organisational-specific measure, acknowledging the importance of employees' commitment to the organisation as a relevant antecedent of well-being (Meyer and Maltin 2010). The subscale reliability was of $\alpha=.86$.

General Well-Being $(G W B)$. The five items that are part of this factor are broadly related to the general feeling of happiness and life satisfaction as individual experiences. An individual's sense of GWB will be to some degree independent of their work situation, and will both influence, and be influenced by, his/her work experience (Easton \& Van Laar 2012). The sub-scale reliability was of $\alpha=.90$.

Covariates. We added age, gender, tenure and position in the University rankings as covariates in the model as they can influence the different factors within quality of working life. Age was measured as a categorical variable, where 1 = 'under twenty-five', 2 = 'twentyfive to forty-four', $3=$ 'forty-five to fifty-nine' and $4=$ 'sixty or over'. Age was included in the module as previous research has demonstrated it is related to employee well-being (e.g. Warr 1992). Gender ( $1=$ male; 2 = female $)$ was also included as a covariate due to its relationships with factors within quality of working life, such as home-work interface also referred to as work-family conflict (Duxbury and Higgins 1991). Tenure was measured as a categorical variable representing the number of years worked in the University, where $1=$ 'less than one', 2 = 'one to two', 3 = 'three to five', 4 = 'six to ten', 5 = 'eleven to twenty', 6 $=$ 'more than twenty'. Tenure would be strongly associated increased job security as it is related to tenure status, which would be extremely relevant for permanent (O'Laughlin \& 
Bishoff 2005), though not necessarily for temporary academics and researchers (H3).

Position in the University rankings was included as an additional covariate in accordance with our final hypothesis (H4). The average position of one's University in the UK University rankings (see data collection for details) can be associated with most aspects of quality of working life, in particular job and career satisfaction, home-work interface, working conditions and organisational commitment.

\section{Data analysis}

Structural equation modelling (SEM) with the IBM SPSS AMOS software package (Arbuckle 2012) was used to test and compare various competing models. Analysis were conducted using the Maximum Likelihood (ML) iteration procedure. SEM has the advantage of providing global measures of fit for latent variable models. As proposed by Anderson and Gerbing (1988), we followed a two-step approach to analyse our results. First, we tested several measurement models through confirmatory factor analysis (CFA), and then compared competing structural models.

The degree of model-fit was assessed using different fit indices. A non-significant or small chi-square $\left(\chi^{2}\right)$ value indicates that the model fits the data well. However, in large samples even small differences between the estimated model and the 'true' underlying model will result in rejection of the model that is tested (Bentler and Chou 1987). Therefore, we also considered other indices in judging the fit of our models, the Tucker-Lewis Index (TLI), the Comparative Fit Index (CFI), the Root Mean Square Error of Approximation (RMSEA), and the standardised root mean square residual (SRMR). CFI and TLI values of 0.90 indicate an acceptable fit and values higher than 0.95 a good fit. RMSEA and SRMR values of 0.10 indicate a mediocre fit, between 0.06 and 0.08 an acceptable fit, and lower than 0.06 a good fit (Hu and Bentler 1999). 
At an initial stage, we performed a multi-group confirmatory factor analysis (CFA) on the full hypothesised measurement model. This model (MM1) included seven factors representing each of the dimensions within quality of working life (HWI, WCS, JCS, CAW, SAW, ECO and GWB) and four single indicators representing age, gender, tenure and position in the University rankings. The latent variables and the four single indicators were allowed to correlate with each other. We then conducted a Harman's single-factor test (Podsakoff et al. 2003), which involves a CFA in which all variables are allowed to load onto one general factor (MM2 = one-factor model). Afterwards, we ran an additional measurement model (MM3) in which all indicators representing quality of working life loaded on one single factor, but indicators referring to age, gender, tenure and position in the University rankings were left as separate variables. In addition, we ran another alternative model with a plausible factor structure for the different quality of working life indicators. In particular, MM4 had four separate indicators representing age, gender, tenure and position in the University rankings and three factors: HWI, WCS, JCS and CAW-related items (as antecedents in the structural theoretical model) loaded on a single factor; SAW and ECOrelated factors (as mediators in the structural model) loaded on another factor; and GWBrelated items (as outcomes) loaded on another factor.

For the purpose of hypotheses testing, we first tested the structural model separately for the subsamples of permanent and temporary workers. We tested our hypothesised structural model which included direct structural paths from HWI, WCS, JCS and CAW to ECO and SAW, and from ECO and SAW to GWB. After verifying whether the model had an adequate fit in the two samples separately, it was then tested in a multiple group analysis including both subsamples in order to assess invariance across the subsamples (baseline model). We have then compared three models with different constraints: (1) the fully unconstrained baseline model, where all parameters were allowed to differ in the two groups; 
(2) a fully constrained model, where all parameters were constrained to equality in the two groups; and (3) a model where only regression weights between our covariates and latent variables, and regression weights among latent variables were unconstrained. We finally inspected the critical ratios for differences between parameters in order to test the hypotheses that some regression paths are different in the two groups (Arbuckle 2012).

\section{Results}

\section{Measurement models and descriptive statistics}

Table 1 presents the goodness-of-fit of competing measurement models. We have first verified that our theoretical measurement model (MM1) with seven factors and four separate indicators had an acceptable fit $\left(\chi^{2}{ }_{(708)}=1339.89 * * * ;\right.$ TLI $=.91 ;$ CFI $=.93 ;$ RMSEA $=.04$; SRMR $=.05)$. In order to control for common method variance and to establish discriminant validity (Podsakoff et al. 2003) we have compared MM1 with MM2, MM3 and MM4, by performing chi-square difference tests. Our theoretical measurement model was significantly more robust than the competing measurement models, which indicates that the factor structures of the quality of working life were consistent with the previously validated structure of the scale and that the indicators loaded on the latent variables as intended, leaving our additional covariates as separate indicators.

\section{[Table 1 near here]}

Appendix 2 shows the means, standard deviations and correlation matrix obtained separately for permanent and temporary workers. As expected, all factors within quality of working life were significantly and highly correlated to each other among both permanent and temporary workers. We have also verified strong correlations between tenure and average position on the University rankings and the different variables within quality of working life. In order to test $\mathrm{H} 2 \mathrm{a}$ ) we conducted independent samples t-tests where we 
compared the means in each variable in the model among permanent and temporary academics and researchers: gender $(\mathrm{t}=-4.32 ; \mathrm{p}<.001)$; age $(\mathrm{t}=12.43 ; \mathrm{p}<.001)$; tenure $(\mathrm{t}=12.68$; $\mathrm{p}<.001)$; average University position in the rankings $(\mathrm{t}=6.93 ; \mathrm{p}<.001)$; HWI $(\mathrm{t}=-3.70$; $\mathrm{p}<.001) ; \mathrm{WCS}(\mathrm{t}=-3.44 ; \mathrm{p}<.001) ; \operatorname{JCS}(\mathrm{t}=-4.45 ; \mathrm{p}<.001) ; \operatorname{CAW}(\mathrm{t}=-3.49 ; \mathrm{p}<.01) ;$ SAW $(\mathrm{t}=6.07 ; \mathrm{p}<.01) ; \operatorname{ECO}(\mathrm{t}=-3.74 ; \mathrm{p}<.001) ; \mathrm{GWB}(\mathrm{t}=-2.30 ; \mathrm{p}<.05)$. These results suggest that temporary workers report higher scores in terms of almost every aspect within quality of working life, except for the absence of stress at work (i.e., permanent workers report lower levels of stress), which is consistent with previous research and supports $\mathrm{H} 2 \mathrm{a}$ ).

In order to account for the possible influence of role (i.e, being an academic or a researcher) in our results, we conducted further analyses. Considering the distributions of academics and researchers across the two contract types, we have created a new categorical variable with four groups: temporary researchers (186), temporary academics (69), permanent researchers (12) and permanent academics (243). We conducted an ANOVA and Fisher's least significance post-hoc tests in order to compare the means of different groups in all our control variables and main studied variables. We found no significant differences between temporary researchers and temporary academics regarding their means in all main variables. The exception was the fact that temporary researchers were younger and employed by higher ranked universities, when compared to temporary academics. Permanent academics and researchers did not significantly differ regarding any of the control nor main variables.

\section{Structural models}

The hypothesised structural model included direct structural paths from HWI, WCS, JCS and CAW to ECO and SAW, and from ECO and SAW to GWB, as well as direct structural paths from gender, age, tenure and average position of the University in the rankings to each of the latent variables. This model was tested separately in the group of permanent workers and in 
the group of temporary workers, and had an acceptable fit to the data in both samples $\left(\right.$ Permanent: $\chi^{2}{ }_{(359)}=754.18 * * * ; \mathrm{TLI}=.90 ; \mathrm{CFI}=.92 ; \mathrm{RMSEA}=.07 ; \mathrm{SRMR}=.05$; Temporary: $\left.\chi^{2}{ }_{(359)}=658.67 * * * ; \mathrm{TLI}=.91 ; \mathrm{CFI}=.92 ; \mathrm{RMSEA}=.06 ; \mathrm{SRMR}=.05\right)$. The model was then tested in a multiple group analysis presenting an acceptable fit $\left(\chi^{2}(718)=\right.$ $\left.1412.85^{* * *} ; \mathrm{TLI}=.90 ; \mathrm{CFI}=.92 ; \mathrm{RMSEA}=.04 ; \mathrm{SRMR}=.05\right)$. In the following step we added constraints to inspect invariance across groups. We have first verified that a fully constrained model (i.e. a model where all regression paths in the model where constrained to be equal in the two groups) had a significantly worse fit than the hypothesised unconstrained structural model (Fully constrained: $\chi^{2}{ }_{(747)}=1471.19 * * * ; \mathrm{TLI}=.90 ; \mathrm{CFI}=.92 ; \mathrm{RMSEA}=$ $.04 ;$ SRMR $=.05$ / Fully unconstrained vs Fully constrained: $\left.\Delta \chi^{2}(29)=58.34, \mathrm{p}<.001\right)$. On a second step, we compared our fully unconstrained model with a model where only regression weights between our covariates and latent variables, and regression weights among latent variables were unconstrained $\left(\chi^{2}{ }_{(737)}=1449.01 * * * ; \mathrm{TLI}=.90 ; \mathrm{CFI}=.92 ; \mathrm{RMSEA}=.04\right.$; SRMR $=.05)$. The chi-squared difference test demonstrated that our fully unconstrained model was similar to this last alternative model, but the differences between the two models were still significant at $\mathrm{p}<.05\left(\Delta \chi^{2}(19)=36.16, \mathrm{p}<.05\right)$. Thus, we chose our fully unconstrained model in order to compare the two groups. Figure 1 portrays the final standardised estimates between latent variables for the two groups in the model. For ease of presentation, the regression paths between age, gender, tenure and average position of the University in the rankings are shown on a separate table, together with critical ratios for differences (Appendix 3). $\mathrm{R}^{2}$ values were .92 to ECO, .82 to SAW and .74 to GWB for permanent workers and .87 to ECO, .69 to SAW and .59 to GWB for temporary workers.

[Figure 1 near here]

Our results partially support H1a) as they demonstrate significant positive relationships between the predictors HWI and WCS, and the absence of SAW among 
permanent workers. However, JCS was negatively related to the absence of stress at work, and CAW was not significantly related to the absence of SAW for this group of workers. For temporary workers only a balanced HWI was related to the absence of SAW. H1b) was also partially supported: WCS were positively related to ECO among both permanent and temporary workers. None of the remaining regression paths were significant among temporary workers. For permanent workers, JCS was positively related to ECO, as expected, but a balanced HWI was negatively related to ECO. H1c) was fully supported as the absence of SAW and ECO were positively related to GWB for both groups of employees.

In order to test the mediating roles of the absence of SAW and ECO in the relationships between our predictors (HWI, WCS, JCS and CAW) and our outcome variable (GWB), we inspected the strength of the indirect effects. We tested the significance of the indirect effects using bootstrapping procedures. Unstandardized indirect effects were computed for each of 2000 bootstrapped samples, and the $95 \%$ confidence interval was computed. Indirect effects are presented when all paths within the mediation are significant. For permanent workers the weights of the indirect effects were: HWI to GWB =.21 (CI -.03; $.43)$; WCS to GWB =.56 (CI -.20; 1.12); JCS to GWB =.215 (CI -1.57;1.38). For temporary workers the weights of the indirect effects were: HWI to GWB $=.22(\mathrm{CI}-.69 ; .55)$ and WCS to $\mathrm{GWB}=.46(\mathrm{CI}-.93 ; 3.21)$. When all paths in the mediation were significant, indirect effects were all within the $95 \%$ confidence interval, meaning that we partially support H1d) and H1e).

Afterwards, we inspected the critical ratios for differences between parameters in order to test hypothesis $\mathrm{H} 2 \mathrm{~b}$ ), which anticipated that the different work characteristics would have a weaker impact on employee commitment to the organisation, for temporary workers, when compared to permanent workers, due to the transitory nature of their contract. Our results reject this hypothesis as they demonstrate that only a balanced HWI is significantly 
different as a predictor of commitment among the two groups. In particular, a balanced HWI seems to not be significantly related to commitment among temporary workers, but it is negatively related to commitment among permanent workers.

H3 was partially supported by our results as we found that tenure was significantly and negatively related to a balanced HWI, to CAW, WCS and JCS. Furthermore, our critical ratios for differences suggest that the effects of tenure are significantly more negative for temporary workers, when compared to permanent workers.

Hypothesis 4 was partially supported in that permanent workers in higher ranked Universities have higher stress levels and temporary workers in higher ranked Universities are more committed to them, but have a lower general well-being. Permanent workers in higher ranked Universities perceive to have more control in terms of decision making at work and better working conditions. Temporary workers in higher ranked Universities also perceive to have better working conditions.

\section{Discussion}

The main aim of this study was to theoretically develop and empirically test a quality of working life mediation model amongst academics and researchers in the UK, considering the role of variables such as contract type, tenure, and position of one's University in the rankings. We collected a sample including permanent and temporary workers, across eight Universities, and ran a SEM multi-group analyses. Our results suggest the existence of a mediation structure wherein specific work-related characteristics first relate to the absence of stress at work (a result explained by the COR theory; Hobfoll 1989) and to commitment to the organisation (a result explained by the social exchange theory; Blau 1964), and these latter variables relate to employee well-being. We were also able to elaborate on the differences between permanent and temporary workers, not only in terms of their mean 
scores in each factor within quality of working life, but also in terms of the relationships among these factors. We found that a longer tenure was particularly negative for temporary workers, when compared to permanent workers. Our results are discussed in more detail in the following paragraphs.

A particularly relevant finding of this study is the existence of significant differences between temporary and permanent workers on the mean scores in each factor within quality of working life. More specifically, temporary workers report higher scores in terms of almost every aspect within quality of working life, except for the absence of stress at work (i.e., permanent workers report lower levels of stress), supporting $\mathrm{H} 2 \mathrm{a}$ ). These results are consistent with previous research (e.g., Bernhard-Oettel, Sverke and De Witte 2005; De Cuyper and De Witte 2006, 2007; De Cuyper, Notelaers and De Witte 2009; De Cuyper et al. 2010; Kirves et al. 2011) and can equally be interpreted in light of the psychological contract: since temporary workers' expectations and perceived obligations were narrower, they are more likely to report more favourable perceptions of their work characteristics, attitudes and even general well-being. However, their perceived stress levels are higher which might be related to the extra effort they could be making in order to move to a permanent job (i.e. stepping stone; De Cuyper, De Witte and Van Emmerick 2011).

Results concerning the differences between permanent and temporary workers on different regression paths will be discussed considering the overall structure of the mediation model. Our results partially supported H1a). We found that a balanced home-work interface was positively related to the absence of stress at work, regardless of the contract type academics and researchers have, which is consistent with previous research (Chiang, Birtch and Kwan 2010). Physical working conditions were only positively related to the absence of stress for permanent workers, but the relationship was not significant for temporary workers. Control over decision making at work was not significantly related to the absence of stress at 
work, for any of the groups, which suggests that this might not be considered a relevant source of stress for academics and researchers. Contrary to expected, job and career satisfaction were negatively related to the absence of stress at work for permanent workers. As previous research suggests, a job in higher education is associated with multiple types of stressors (Taris, Schreurs and Van-Iersel-Van-Silfhout 2001). Our results add to this body of research, by suggesting that a fulfilling job and career in academia is associated with higher levels of stress for academics of researchers.

Concerning the antecedents of employee commitment to the organisation ( $\mathrm{H} 1 \mathrm{~b}$ and $\mathrm{H} 2 \mathrm{~b}$ ), we found that working conditions were positively and significantly related to this variable in both groups, which is consistent with social exchange theory (Blau 1964) and the inherent idea that employees reciprocate perceived inducements provided by the organisation (Gouldner 1960). Job and career satisfaction was positively and significantly related to commitment to the organisation for permanent workers, which can equally be explained by reciprocating the favourable context for job and career development provided by the University, with commitment toward this organisation. Control over decision making at work was not significantly related to organisational commitment for any of the groups, suggesting that this variable is not particularly relevant for academics and researchers. Contrary to what was found in previous research (Huang, Lawler and Lei 2007), we found that a balanced home-work interface was negatively related to organisational commitment among permanent workers, and the relationship was not significant for temporary workers. This negative relationship for the first group indicates that employees who feel that they are having more trouble balancing time spent at work and private life are likely to associate this with their higher commitment to their organisation, as they are likely to work more hours.

As expected, the absence of stress at work was positively related to general wellbeing for both groups (H1c). However, this relationship was stronger for permanent workers, 
when compared with temporary workers. This is associated with our finding that stress at work was the only variable where temporary workers scored higher than permanent workers. Temporary worker's scores for general well-being are still higher, but it seems that the absence of stress at work is a weaker antecedent of general well-being for temporary workers, compared with permanent workers. We hypothesised that the relationship between employee commitment to the organisation and general well-being was positive and significant for the two groups, but there were no differences between the two groups concerning this path. Indirect effects between the independent variables (that were significantly related to the mediators) and general well-being were significant, which partially supports H1d and H1e), indicating that work-related characteristics will first influence, not only occupational health (measured via stress at work), but also attitudes towards the organisation (employee commitment to the organisation), and these will ultimately influence general well-being. Of particular interest that the combined effect of the antecedents in our model explains $74 \%$ of the variance in general well-being for permanent workers and $59 \%$ of the variance in general well-being for temporary workers. This suggests that general well-being is largely explained by work-related aspects, and that this is a comprehensive multifactorial model predicting this variable.

Partially consistent with $\mathrm{H} 3$, we found that a longer tenure in the organisation is negatively related to higher scores in home-work interface, working conditions, job and career satisfaction, and control at work for temporary workers. For permanent workers, tenure was only negatively related to job and career satisfaction. The relationships between tenure and the supra-mentioned variables were significantly stronger for temporary workers. This interesting result suggests that temporary workers who have been in a temporary contract for too long are likely to perceive their position as a dead end rather than a stepping 
stone (De Cuyper, De Witte and Van Emmerick 2011), resulting in an overall more negative perception of their work-related characteristics.

Finally, the average position of respondents' university in the UK rankings was negatively related to working conditions, meaning that the higher the position in the ranking the more favourable the scores on working conditions for both permanent and temporary workers. Permanent workers in lower ranked Universities have less stress at work, which may be due to the fact that lower ranked Universities are less likely to transmit pressure in terms of the need for academic publications. Temporary workers in higher ranked universities are more committed to these institutions, which may be related to their prestige or to the fact that these workers may have completed part of their education in these institutions.

\section{Limitations and future research directions}

This study has two main limitations that should be acknowledged. First, we used selfreported questionnaires exclusively, which could potentially affect the results, due to common method variance. However, in order to minimize this effect, all methodological and statistical recommendations by Podsafoff et al. (2003) were followed. For example, we used confirmatory factor analysis and compared several competing models, which reassures us that the factorial structure of the model is robust. Furthermore, we have focused on objective indicators as covariates in our model, including age, gender, tenure and average university position in the UK rankings, which acknowledges the influence of non-perceptual elements that could (and did) influence our results. Further research should consider the role of other objective variables that may influence quality of working life, such as pay and objective performance indicators. The second limitation of this study lies on using a cross-sectional design, which does not allow us to verify the existence of causal relationships between the variables. However, the rationale behind our mediation model was supported by two robust 
theoretical frameworks (i.e. COR theory - Hobfoll 1989; and social exchange theory - Blau 1964) and by multiple empirical findings that support the directionality of relationships between variables in our model. Future research should consider the confirmation of the directionality of these paths in a longitudinal design. The third limitation of this study is the fact that although our results can be a good portrait of the quality of working life in British Universities, these results may not necessarily be the same in other countries (e.g., the USA where labour legislation tends to be less protective, or Continental Europe where labour legislation tends to be more protective). Further research should expand these results in different contexts.

\section{Concluding remarks and practical implications}

Our study contributes to existing research by advancing a model that integrates multiple empirical findings regarding quality of working life and explains the processes within it in the specific context of higher education in the UK. It contributes to the literature on work in higher education by comparing permanent and temporary academics and researchers. Our results suggest that permanent and temporary workers differ in terms of the processes leading to general well-being, with particular emphasis on high stress levels of academics and researchers on fixed-term contracts. Furthermore, we note the finding of a longer tenure being more negative for temporary workers, suggesting that they may feel trapped in a fixed-term position, without a possibility of a stepping stone to a permanent position. These results are relevant for human resource management in higher education institutions as they identify the work related characteristics that might usefully be addressed in an endeavour to improve the quality of working life of academics and researchers, and reiterate the need to adequately manage the expectations of those on fixed-term contracts. 


\section{References}

Anderson, J. C., and D. W. Gerbing. 1988. "Structural equation modelling in practice: A review and recommended two-step approach.” Psychological Bulletin, 103(3): 411423. doi: 10.1037/0033-2909.103.3.411

Andolsek, D. M. and J. Stebe, J. 2004. "Multinational perspectives on work values and commitment." International Journal of Cross Cultural Management, 4(2): 181-209. doi: $10.1177 / 1470595804044749$

Arbuckle, J. L. 2012. IBM SPSS AMOS 21 User's Guide. Amos Development Corporation and IBM Corporation.

Bentler, P. M. and C. P. Chou. 1987. "Practical issues in structural equation modelling." Sociological Methods and Research, 16(1): 78-117. doi: $10.1177 / 0049124187016001004$

Bernhard-Oettel, C., M. Sverke, and H. De Witte. 2005. "Comparing three alternative types of employment with permanent full-time work: how do employment contract and perceived job conditions relate to health complaints?" Work \& Stress, 19(4): 301318. doi: 10.1080/02678370500408723

Blanch, J. M., M. Sahagún, L. Cantera, and G. Cervantes. 2010. “Questionnaire of general labour well- being: Structure and psychometric properties.” Revista de Psicología del Trabajo y de las Organisaciones, 26(2): 157-170.

Blau, P. M. 1964. Exchange and power in social life. NY: John Wiley \& Sons.

Borg, M. G., R. J. Riding, and J. M. Falzon. 1991. "Stress in teaching: A study of occupational stress and its determinants, job satisfaction and career commitment among primary schoolteachers.” Educational Psychology, 11(1): 59-75. doi: $10.1080 / 0144341910110104$ 
Brown, T. A. 2006. Confirmatory Factor Analysis for Applied Research. New York: Guilford.

Cheng, G.H.L. and D. K. S. Chan. 2008. "Who suffers more from job insecurity? A metaanalytic review.” Applied Psychology, 57(2): 272-303. doi: 10.1111/j.14640597.2007.00312.x

Chiang, F.F.T., T. A. Birtch, and H. K. Kwan. 2010. "The moderating roles of job control and work-life balance practices on employee stress in the hotel and catering industry." International Journal of Hospitality Management, 29(1): 25-32. doi: 10.1016/j.ijhm.2009.04.005

Daniels, K. and A. Guppy. 1994. “Occupational stress, social support, job control and psychological well-being." Human Relations, 47(12): 1523-1544. doi: $10.1177 / 001872679404701205$

De Cuyper, N., J. De Jong, H., De Witte, K. Isaksson, T. Rigotti, and R. Schalk. 2008. "Literature review of theory and research on the psychological impact of temporary employment: Towards a conceptual model.” International Journal of Management Reviews, 10(1): 25-51. doi: 10.1111/j.1468-2370.2007.00221.x

De Cuyper, N., and H. De Witte. 2006. "The impact of job insecurity and contract type on attitudes, well-being and behavioural reports: a psychological contract perspective." Journal of Occupational and Organizational Psychology, 79(3): 395-409. doi: $10.1348 / 096317905 X 53660$

De Cuyper, N. and H. De Witte. 2007. "Job insecurity in temporary versus permanent workers: associations with well-being, attitudes and behaviour." Work \& Stress, 21(1): 65-84. doi: 10.1080/02678370701229050

De Cuyper, N., H. De Witte, U. Kinnunen, and J. Nätti. 2010. “The relationships between job insecurity, employability and well-being in Finnish temporary and permanent 
employees.” International Studies of Management and Organization, 40(1): 57-73. doi: 10.2753/IMO0020-8825400104

De Cuyper, N., H. De Witte, and H., Van Emmerick. 2011. “Temporary employment: costs and benefits for (the careers of) employees and organizations." Career Development International, 16(2): 104-113. doi: 10.1108/13620431111115587

De Cuyper, N., G. Notelaers, and H. De Witte. 2009. "Job insecurity and employability in fixed-term contractors, agency workers, and permanent workers: associations with job satisfaction and affective organizational commitment.” Journal of Occupational Health Psychology, 14(2): 193-205. doi: 10.1037/a0014603

Dehghan, N., S. Tahmineh, and N. Asadi. 2011. "Quality of work life and productivity among Iranian nurses.” Contemporary Nurse, 39(1): 106-118. doi: 10.5172/conu.2011.39.1.106

Demerouti, E., A. B. Bakker, F. Nachreiner, and W. Schaufeli. 2001. "The job demandsresources model of burnout.” Journal of Applied Psychology, 86(3): 499-512. doi: 10.1037/0021-9010.86.3.499

Duxbury, L. E. and C. A. Higgins. 1991. "Gender differences in work-family conflict." Journal of Applied Psychology, 76(1): 60-74. doi: 10.1037/0021-9010.76.1.60

Easton, S. and D. L. Van Laar. 2012. User manual for the Work-Related Quality of Life (WRQoL) scale. Portsmouth, UK: University of Portsmouth.

Easton, S. and D. L. Van Laar. 2013. "Evaluation of outcomes and quality of working life in the coaching setting.” The Coaching Psychologist, 9(2): 71-77.

Edwards, J., D. L. Van Laar, S. Easton, and G. Kinman. 2009. “The work-related quality of life scale for higher education employees.” Quality in Higher Education, 15(3): 207219. doi: $10.1080 / 13538320903343057$ 
Evans, G.W. and D. Johnson. 2000. "Stress and open-office noise.” Journal of Applied Psychology, 85(5): 779-783.

Galais, N. and K. Moser. 2009. "Organizational commitment and the well-being of temporary agency workers: A longitudinal study.” Human Relations, 62(4): 589-620. doi: $10.1177 / 0018726708101991$

Gillespie, N. A., M. Walsh, A. H. Winefield, J. Dua, and C. Stough. 2001. “Occupational stress in universities: Staff perceptions of the causes, consequences and moderators of stress.” Work \& Stress, 15(1): 52-72. doi: 10.1080/02678370117944

Gouldner, A.W. 1960. “The Norm of Reciprocity: A Preliminary Statement.” American Sociological Review, 25(2), pp.161-178. Accessed February 252016 http://www.jstor.org/stable/2092623

Guest, D. 2004. "Flexible employment contracts, the psychological contract and employee outcomes: an analysis and review of the evidence.” International Journal of Management Reviews, 5(6): 1-19.

Hobfoll, S.E. 1989. "Conservation of resources: A new attempt at conceptualizing stress." American Psychologist, 44(3): 513-524. doi: 10.1037/0003-066X.44.3.513

Hu, L., and Bentler, P. M. (1999). Cutoff criteria for fit indexes in covariance structure analysis: Conventional criteria versus new alternatives, 6(1): 1-55. doi: $10.1080 / 10705519909540118$

Huang, T.-C., J. Lawler, and C.-Y. Lei. 2007. "The effects of quality of work-life on commitment and turnover intention." Social Behavior and Personality, 35(6): 735750.

Kinman, G., F. Jones, and R. Kinman. 2006. The well-being of the UK academy, 1998-2004. Quality in Higher Education, 12(1): 15-27. doi: 10.1080/13538320600685081 
Kirves, K., N. De Cuyper, U. Kinnunen and J. Nätti. 2011. "Perceived job insecurity and perceived employability in relation to temporary and permanent workers' psychological symptoms: a two samples study." International Archives of Occupational and Environmental Health, 84(8): 899-909. doi: 10.1007/s00420-0110630-y

Karasek, R.A. 1979. "Job demands, job decision latitude and mental strain: implications for job redesign.” Administrative Science Quarterly, 24(2): 285-308. doi: $10.2307 / 2392498$

Lewis, S., R. Gambles, and R. Rapoport. 2007. "The constraints of a 'work-life balance' approach: An international perspective.” The International Journal of Human Resource Management, 18(3): 360-373. doi: 10.1080/09585190601165577

McGuire, D. and L. McLaren. 2009. "The impact of physical environment on employee commitment in call centres: The mediating role of employee well-being." Team Performance Management: An International Journal, 15(1/2): 35-48. doi: $10.1108 / 13527590910937702$

Meyer, J. P. and N. J. Allen. 1997. Commitment in the workplace: Theory, research, and application. Thousand Oaks, CA: Sage.

Meyer, J. P., and E. R. Maltin. 2010. "Employee commitment and well-being: A critical review, theoretical framework and research agenda." Journal of Vocational Behavior, 77(2): 323-337. doi: 10.1016/j.jvb.2010.04.007

Meyer, J. P., D. J. Stanley, L. Herscovitch, and L. Topolnytsky. (2002). “Affective, Continuance, and Normative Commitment to the Organization: A Meta-analysis of Antecedents, Correlates, and Consequences.” Journal of Vocational Behavior, 61(1): 20-52. doi: $10.1006 /$ jvbe.2001.1842 
O’Laughlin, E. M. and L. G. Bischoff. 2005. “Balancing parenthood and academia:

Work/family stress as influenced by gender and tenure status.” Journal of Family Issues, 26(1): 79-106. doi: 10.1177/0192513X04265942

Podsakoff, P.M., S. B. MacKenzie, J. Y. Lee, and N. P. Podsakoff. 2003. “Common method biases in behavioral research: A critical review of the literature and recommended remedies.” Journal of Applied Psychology, 88(5): 879-903. doi: 10.1037/00219010.88.5.879

Rousseau D. M. 1995. Psychological contracts in organizations: understanding written and unwritten agreements. Thousand Oaks: Sage.

Spector, P. E. 2002. "Employee control and occupational stress.” Current Directions in Psychological Science, 11(4): 133-136. doi: 10.1111/1467-8721.00185

Sverke, M., J. Hellgren, and K. Näswall. 2002. "No security: a meta-analysis and review of job insecurity and its consequences." Journal of Occupational Health Psychology, 7(3): 242-264. doi: 10.1037/1076-8998.7.3.242

Taris, T. W., P. J. G. Schreurs, and I. J. Van Iersel-VanSilfhout. 2001. “Job stress, job strain, and psychological withdrawal among Dutch university staff: Towards a dual process model for the effects of occupational stress.” Work \& Stress, 15(4): 283-296. doi: $10.1080 / 02678370110084049$

Turban, D.B., and D. W. Greening. 1997. "Corporate social performance and organizational attractiveness to prospective employees.” Academy of Management Journal, 40(3): 658-673. doi: $10.2307 / 257057$

Tytherleigh, M. Y., C. Webb, C. L. Cooper, and C. Ricketts. 2005. “Occupational stress in UK higher education institutions: A comparative study of all staff categories.” Higher Education Research and Development, 24(1): 41-61. doi: $10.1080 / 0729436052000318569$ 
Warr, P. 1992. “Age and occupational well-being.” Psychology and Aging, 7(1):37-45. doi: 10.1037/0882-7974.7.1.37

Vagharseyyedin, S.A., Z. Vanaki, and E. Mohammadi. 2011. "Quality of work life:

Experiences of Iranian nurses.” Nursing and Health Sciences, 13(1): 65-75. doi:

10.1111/j.1442-2018.2011.00581.x

Zaffane, R. 1994. "Patterns of organizational commitment and perceived management style:

A comparison of public and private sector employees." Human Relations, 47(8): 9771010. doi: $10.1177 / 001872679404700806$

Zhang, L.F. 2007. "Teaching styles and occupational stress among Chinese university faculty members." Educational Psychology, 27(6): 823-841. doi:

$10.1080 / 01443410701366043$ 
Table 1. Goodness-of-fit of measurement models (best fitting measurement model in bold).

\begin{tabular}{|c|c|c|c|c|c|c|}
\hline Models & $\chi^{2}$ & $\Delta \chi^{2}$ & TLI & CFI & RMSEA & SRMR \\
\hline MM1 & $\chi^{2}(708)=1339.89 * * *$ & & .91 & .93 & .04 & .05 \\
\hline MM2 & $\chi^{2}(810)=3148.44 * * *$ & $\begin{array}{l}\text { Compared to MM1 } \\
\Delta \chi^{2}{ }_{(102)}=1808.55^{* * *}\end{array}$ & .71 & .73 & .08 & .08 \\
\hline MM3 & $\chi^{2}{ }_{(798)}=3079.31 * * *$ & $\begin{array}{l}\text { Compared to MM1 } \\
\Delta \chi^{2}(90)=1739.42 * * *\end{array}$ & .71 & .74 & .08 & .08 \\
\hline MM4 & $\chi^{2}(776)=2574.99 * * *$ & $\begin{array}{l}\text { Compared to MM1 } \\
\Delta \chi^{2}{ }_{(68)}=1236^{* * *}\end{array}$ & .77 & .79 & .07 & .08 \\
\hline
\end{tabular}

Note: $*=\mathrm{p}<.05 ; * *=\mathrm{p}<.01 ; * * *=\mathrm{p}<.001$

Figure 1. Final Structural Model (covariates omitted for ease of presentation)

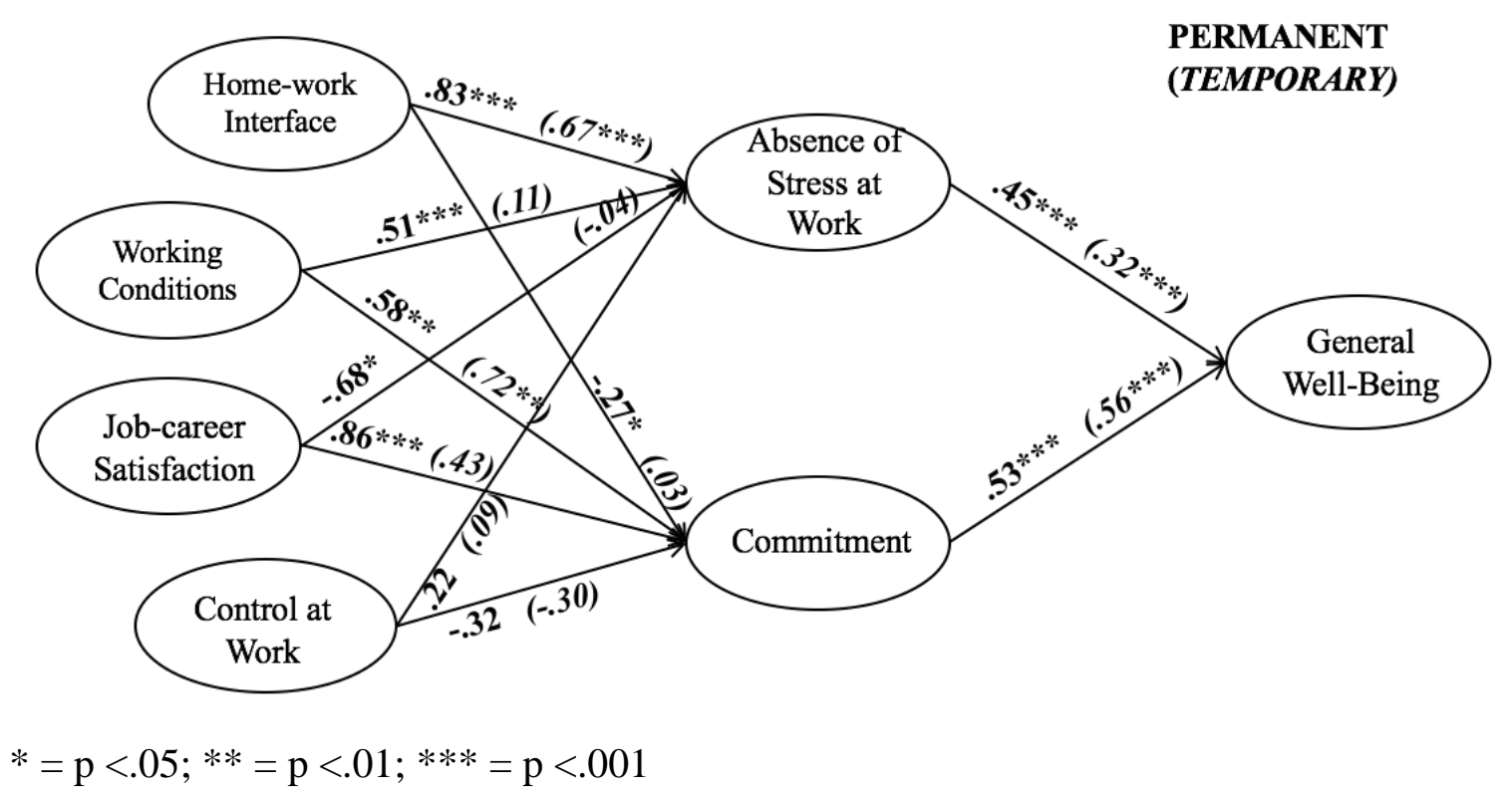


Appendix 1. Quality of Working Life Items

\begin{tabular}{|c|c|c|}
\hline Factor & Items & $\begin{array}{l}\text { Factor } \\
\text { Loadings }\end{array}$ \\
\hline \multirow[t]{3}{*}{ HWI } & $\begin{array}{l}\text { I am able to achieve a healthy balance between my work and home } \\
\text { life }\end{array}$ & .87 \\
\hline & $\begin{array}{l}\text { My current working hours / patterns suit my personal } \\
\text { circumstances }\end{array}$ & .82 \\
\hline & $\begin{array}{l}\text { My employer provides adequate facilities and flexibility for me to } \\
\text { fit work in around my family life }\end{array}$ & .75 \\
\hline \multirow[t]{3}{*}{ WCS } & The working conditions are satisfactory & .84 \\
\hline & I work in a safe environment & .60 \\
\hline & $\begin{array}{l}\text { My employer provides me with what I need to do my job } \\
\text { effectively }\end{array}$ & .79 \\
\hline \multirow[t]{5}{*}{ JCS } & I have a clear set of goals and aims to enable me to do my job & .68 \\
\hline & $\begin{array}{l}\text { When I have done a good job it is acknowledged by my line } \\
\text { manager }\end{array}$ & .72 \\
\hline & I am encouraged to develop new skills & .70 \\
\hline & I am satisfied with the career opportunities available for me here & .77 \\
\hline & $\begin{array}{l}\text { I am satisfied with the training I receive in order to perform my } \\
\text { present job }\end{array}$ & .71 \\
\hline \multirow[t]{3}{*}{ CAW } & $\begin{array}{l}\text { I have sufficient opportunities to question managers about change } \\
\text { at work }\end{array}$ & .79 \\
\hline & I am involved in decisions that affect me in my own area of work & .85 \\
\hline & $\begin{array}{l}\text { I feel able to voice opinions and influence changes in my area of } \\
\text { work }\end{array}$ & .87 \\
\hline \multirow[t]{4}{*}{ SAW } & I have unachievable deadlines (-rev) & .63 \\
\hline & I am pressured to work long hours (-rev) & .72 \\
\hline & I often feel under pressure at work (-rev) & .75 \\
\hline & I often feel excessive levels of stress at work (-rev) & .83 \\
\hline \multirow[t]{3}{*}{ ECO } & I would recommend this organisation as a good one to work for & .94 \\
\hline & I am proud to tell others that I am part of this organisation & .88 \\
\hline & The organisation communicates well with its employees & .74 \\
\hline \multirow[t]{5}{*}{ GWB } & I feel well at the moment & .79 \\
\hline & I am satisfied with my life & .80 \\
\hline & In most ways my life is close to ideal & .84 \\
\hline & Generally things work out well for me & .75 \\
\hline & $\begin{array}{l}\text { Recently, I have been feeling reasonably happy all things } \\
\text { considered }\end{array}$ & .87 \\
\hline
\end{tabular}


Appendix 2. Correlations and Descriptive Statistics for Permanent and Temporary academics and researchers

\begin{tabular}{|c|c|c|c|c|c|c|c|c|c|c|c|c|c|}
\hline \multicolumn{14}{|c|}{ Permanent } \\
\hline & $\mathrm{M}$ & SD & Gender & Age & Tenure & URank & HWI & WCS & JCS & CAW & $\mathrm{ECO}$ & SAW & GWB \\
\hline Gender & --- & --- & 1 & & & & & & & & & & \\
\hline Age Category & 2.70 & .60 & -.04 & 1 & & & & & & & & & \\
\hline Tenure & 3.23 & 1.16 & -.12 & $.38 * * *$ & 1 & & & & & & & & \\
\hline URank & 69.15 & 42.59 & -.06 & .06 & .12 & 1 & & & & & & & \\
\hline HWI & 3.20 & 1.00 & .01 & -.08 & $-.14 *$ & -.05 & 1 & & & & & & \\
\hline WCS & 3.34 & 0.89 & -.05 & -.08 & $-.13^{*}$ & $-.18 * *$ & $.65 * * *$ & 1 & & & & & \\
\hline JCS & 3.01 & 0.88 & .05 & $-.16^{*}$ & $-.20 * *$ & -.10 & $.62 * * *$ & $.72 * * *$ & 1 & & & & \\
\hline CAW & 3.15 & 1.04 & -.02 & -.10 & $-.13 *$ & $-.17 * *$ & $.54 * * *$ & $.68 * * *$ & $.76^{* * *}$ & 1 & & & \\
\hline ECO & 3.03 & 1.04 & .08 & -.06 & $-.21 * *$ & $-.23^{* * *}$ & $.56 * * *$ & $.76^{* * *}$ & $.78 * * *$ & $.70 * * *$ & 1 & & \\
\hline Absence SAW & 2.62 & 0.87 & -.05 & -.02 & -.12 & .01 & $.70 * * *$ & $.57 * * *$ & $.49 * * *$ & $.44 * * *$ & $.44 * * *$ & 1 & \\
\hline GWB & 3.23 & 0.93 & -.02 & -.12 & $-.14 *$ & -.06 & $.71 * * *$ & $.74 * * *$ & $.68 * * *$ & $.59 * * *$ & $.65 * * *$ & $.58 * * *$ & 1 \\
\hline \multicolumn{14}{|c|}{ Temporary } \\
\hline & $\mathrm{M}$ & SD & Gender & Age & Tenure & URank & HWI & WCS & JCS & CAW & ECO & SAW & GWB \\
\hline Gender & --- & --- & 1 & & & & & & & & & & \\
\hline Age Category & 2.11 & .46 & -.08 & 1 & & & & & & & & & \\
\hline Tenure & 2.10 & .81 & -.11 & $.23 * * *$ & 1 & & & & & & & & \\
\hline URank & 47.22 & 27.27 & -.06 & $.15^{*}$ & -.08 & 1 & & & & & & & \\
\hline HWI & 3.52 & .95 & -.02 & -.02 & $-.23 * * *$ & .00 & 1 & & & & & & \\
\hline WCS & 3.60 & .82 & $.12^{*}$ & $-.15^{*}$ & $-.32 * * *$ & -.12 & $.55^{* * *}$ & 1 & & & & & \\
\hline JCS & 3.35 & .84 & .10 & -.10 & $-.43 * * *$ & -.02 & $.49 * * *$ & $.68 * * *$ & 1 & & & & \\
\hline CAW & 3.45 & .89 & .09 & .04 & $-.32 * * *$ & -.06 & $.46^{* * *}$ & $.55 * * *$ & $.70 * * *$ & 1 & & & \\
\hline ECO & 3.35 & .86 & $.16^{*}$ & -.10 & $-.30 * * *$ & $-.19^{* * *}$ & $.48 * * *$ & $.70 * * *$ & $.64 * * *$ & $.47 * * *$ & 1 & & \\
\hline Absence SAW & 3.10 & .93 & -.06 & $-.14 *$ & $-.33 * * *$ & .04 & $.64 * * *$ & $.49 * * *$ & $.46 * * *$ & $.44 * * *$ & $.44 * * *$ & 1 & \\
\hline GWB & 3.41 & .86 & .10 & -.05 & $-.29 * * *$ & .00 & $.61 * * *$ & $.62 * * *$ & $.62 * * *$ & $.49 * * *$ & $.56^{* * *}$ & $.52 * * *$ & 1 \\
\hline
\end{tabular}

Note: $*=\mathrm{p}<.05 ; * *=\mathrm{p}<.01 ; * * *=\mathrm{p}<.001 ;$ URank $=$ University's average position in the main rankings 
Appendix 3. Regression weights and critical ratios for differences for all regression paths in the model

\begin{tabular}{|c|c|c|c|}
\hline Path & Permanent & Temporary & $\begin{array}{l}\text { Critical Ratios for } \\
\text { Differences }\end{array}$ \\
\hline HWI $\rightarrow$ Absence of SAW & $\beta=.83 * * *$ & $\beta=.67 * * *$ & $\mathrm{Z}=-0.13$, n.s. \\
\hline WCS $\rightarrow$ Absence of SAW & $\beta=.51 * * *$ & $\beta=.11$, n.s. & $\mathrm{Z}=-0.95$, n.s. \\
\hline $\mathrm{JCS} \rightarrow$ Absence of SAW & $\beta=-.68^{*}$ & $\beta=-.04$, n.s. & $\mathrm{Z}=1.40$, n.s. \\
\hline $\mathrm{CAW} \rightarrow$ Absence of SAW & $\beta=.22$, n.s. & $\beta=.09$, n.s. & $\mathrm{Z}=-0.22$, n.s. \\
\hline $\mathrm{HWI} \rightarrow \mathrm{ECO}$ & $\beta=-.27 *$ & $\beta=.03$, n.s. & $\mathrm{Z}=2.16^{*}$ \\
\hline $\mathrm{WCS} \rightarrow \mathrm{ECO}$ & $\beta=.58 * *$ & $\beta=.72 * *$ & $\mathrm{Z}=0.28$, n.s. \\
\hline $\mathrm{JCS} \rightarrow \mathrm{ECO}$ & $\beta=.86^{* * *}$ & $\beta=.43$ & $\mathrm{Z}=-1.53$, n.s. \\
\hline $\mathrm{CAW} \rightarrow \mathrm{ECO}$ & $\beta=.22$, n.s. & $\beta=-.30$, n.s. & $\mathrm{Z}=-0.09$, n.s. \\
\hline Absence of SAW $\rightarrow$ GWB & $\beta=.45^{* * *}$ & $\beta=.32 * * *$ & $\mathrm{Z}=-2.14^{*}$ \\
\hline $\mathrm{EEN} \rightarrow \mathrm{GWB}$ & $\beta=.53 * * *$ & $\beta=.56^{* * *}$ & $\mathrm{Z}=0.64$, n.s. \\
\hline Age $\rightarrow$ JCS & $\beta=-.10$, n.s. & $\beta=.01$, n.s. & $\mathrm{Z}=0.95$, n.s. \\
\hline Age $\rightarrow$ CAW & $\beta=-.06$, n.s. & $\beta=.16^{*}$ & $\mathrm{Z}=2.28^{*}$ \\
\hline Age $\rightarrow$ WCS & $\beta=-.03$, n.s. & $\beta=-.05$ & $Z=-0.26$, n.s. \\
\hline Age $\rightarrow$ HWI & $\beta=-.02$, n.s. & $\beta=.02$, n.s. & $\mathrm{Z}=-0.32$, n.s. \\
\hline Age $\rightarrow \mathrm{ECO}$ & $\beta=.02$, n.s. & $\beta=.12 *$ & $\mathrm{Z}=0.47$, n.s. \\
\hline Age $\rightarrow$ Absence of SAW & $\beta=.10^{*}$ & $\beta=-.09$, n.s. & $Z=-1.63$, n.s. \\
\hline Age $\rightarrow$ GWB & $\beta=-.11^{*}$ & $\beta=.04$ & $\mathrm{Z}=2.04^{*}$ \\
\hline Gender $\rightarrow$ JCS & $\beta=.03$, n.s. & $\beta=.06$, n.s. & $\mathrm{Z}=0.39$, n.s. \\
\hline Gender $\rightarrow$ CAW & $\beta=-.04$, n.s. & $\beta=.07$, n.s. & $\mathrm{Z}=1.07, \mathrm{n} . \mathrm{s}$ \\
\hline Gender $\rightarrow$ WCS & $\beta=-.08$, n.s. & $\beta=.12$, n.s. & $\mathrm{Z}=2.44^{*}$ \\
\hline Gender $\rightarrow$ HWI & $\beta=-.02$, n.s. & $\beta=-.05$, n.s. & $\mathrm{Z}=-0.31$, n.s. \\
\hline Gender $\rightarrow$ ECO & $\beta=.05$, n.s. & $\beta=.06$, n.s. & $\mathrm{Z}=0.00, \mathrm{n} . \mathrm{s}$ \\
\hline Gender $\rightarrow$ Absence of SAW & $\beta=.00$, n.s. & $\beta=-.11$, n.s. & $\mathrm{Z}=-1.42$, n.s. \\
\hline Gender $\rightarrow$ GWB & $\beta=-.02$, n.s. & $\beta=.03$, n.s. & $\mathrm{Z}=0.74$, n.s. \\
\hline Tenure $\rightarrow$ JCS & $\beta=-.17 *$ & $\beta=-.47 * * *$ & $Z=-4.42 * *$ \\
\hline Tenure $\rightarrow$ CAW & $\beta=-.10$, n.s. & $\beta=-.39 * * *$ & $Z=-2.93 * *$ \\
\hline Tenure $\rightarrow$ WCS & $\beta=-.13$, n.s. & $\beta=-.36 * * *$ & $Z=-2.94 * *$ \\
\hline Tenure $\rightarrow$ HWI & $\beta=-.14$, n.s. & $\beta=-.27 * * *$ & $Z=-2.00 *$ \\
\hline Tenure $\rightarrow \mathrm{ECO}$ & $\beta=-.03$, n.s. & $\beta=.00$, n.s. & $\mathrm{Z}=0.39$, n.s. \\
\hline Tenure $\rightarrow$ Absence of SAW & $\beta=-.09$, n.s. & $\beta=-.11$, n.s. & $\mathrm{Z}=-0.78$, n.s. \\
\hline Tenure $\rightarrow$ GWB & $\beta=.07$, n.s. & $\beta=.00, \mathrm{n} . \mathrm{s}$ & $\mathrm{Z}=-0.73$, n.s. \\
\hline URank $\rightarrow$ JCS & $\beta=-.09$, n.s. & $\beta=-.07$, n.s. & $\mathrm{Z}=-0.33$, n.s. \\
\hline URank $\rightarrow$ CAW & $\beta=-.16^{*}$ & $\beta=-.11$, n.s. & $\mathrm{Z}=0.29, \mathrm{n} . \mathrm{s}$ \\
\hline URank $\rightarrow$ WCS & $\beta=-.18^{* *}$ & $\beta=-.16^{*}$ & $\mathrm{Z}=-0.40$, n.s. \\
\hline URank $\rightarrow$ HWI & $\beta=-.03$, n.s. & $\beta=-.03$, n.s. & $\mathrm{Z}=-0.1, \mathrm{n} . \mathrm{s}$ \\
\hline URank $\rightarrow$ ECO & $\beta=-.11$, n.s. & $\beta=-.12^{*}$ & $Z=-0.65$, n.s. \\
\hline URank $\rightarrow$ Absence of SAW & $\beta=.11^{*}$ & $\beta=.06$, n.s. & $\mathrm{Z}=-0.04$, n.s. \\
\hline URank $\rightarrow$ GWB & $\beta=.07$, n.s. & $\beta=.10^{*}$ & $\mathrm{Z}=0.95$, n.s. \\
\hline
\end{tabular}

Note: $*=\mathrm{p}<.05 ; * *=\mathrm{p}<.01 ; * * *=\mathrm{p}<.001 ;$ n.s. $=$ non-significant; URank $=$ University's average position in the main rankings 